九州大学学術情報リポジトリ

Kyushu University Institutional Repository

\title{
Environmental Impacts of Coal Mining and Preventive Measures in Japan
}

Aoki, Kazuo

Mining and Geotechnology Department, National Research Institute for Pollution and Resources AIST

Esaki, Tetsuro

Faculty of Engineering Kyushu University

Kimura, Tsuyoshi

Faculty of Engineering Kyushu University

Kameda, Nobuhi ro

Faculty of Engineering Kyushu Kyoritsu University

他

https://doi.org/10.15017/6543

出版情報: 九州大学機能物質科学研究所報告. 2(2)，pp. 231-240，1988-12-28. 九州大学機能物質科学 研究所

バージョン：

権利関係: 


\title{
Environmental Impacts of Coal Mining and Preventive Measures in Japan
}

\author{
Kazuo AOKI*, Tetsuro ESAKI**, Tsuyoshi KIMURA**, \\ Nobuhiro KAMEDA*** and Tadashi NISHIDA**
}

\begin{abstract}
This paper describes the characteristics of mine-induced damage in Japan: cave-in, springing out of ground water and subsidence in the area of thick alluvium except usual subsidence. As for the damage of cave-in, preventive measures are also presented. The phenomenon of springing out is discussed with the results of numerical analysis, considering the permeability of mined area.
\end{abstract}

Japan has ten underground coal mines in operation and approximately 1,000 abandoned mines. These mines have caused huge mining damages, and now the Japanese government pays more than four hundred million dollars for restoring the damages every year. However, the remnant damages are estimated at about three billion dollars; this may depend on social and political situations to a certain extent.

Most of the damages are due to normal subsidence, but the change of mining operations such as mining under worse conditions or mine closure has caused new environmental impacts: cave-in due to cavities remaining at shallow depths, springing out of ground water at abandoned mines and subsidence due to mining and dewatering in the area of thick alluvium. These damages were first brought to public notice at the end of the 1970s, though they had occurred before. This paper describes the characteristics of these impacts and some preventive measures against them from a geotechnical point of view.

\section{Cave-in at Shallow Depth}

The ground with old coal workings of ten has many unfilled cavities at shallow depths. The cavities are naturally unstable, while construction of new structures on the ground surface, change in the level of ground water or occurrence of earthquakes accelerates the deterioration of roof strata above the cavities. The deteriorated zones fall into the cavities and extend to the ground surface, and eventually cave-ins occur suddenly.

\footnotetext{
Received December 12, 1988

* Mining and Geotechnology Department, National Research Institute for Pollution and Resources, AIST, MITI, Tsukuba 305

** Faculty of Engineering, Kyushu University, Fukuoka 812

*** Faculty of Engineering, Kyushu Kyoritsu University, Kitakyushu 807
} 
Rainfall. Fig. 1 shows the average monthly frequency distribution of cave-ins, with rainfall, occurring between 1974 and 1987 in the Chikuho district of Kyushu Island, Japan, where a great number of coal mines have been abandoned and many cavities remain at shallow depths. Fifty to sixty cave-ins occurred every year and the frequency increased especially during the rainy season (June to July). This direct relationship between cave-ins and rainfall can be explained by the effective pore pressure in the ground.

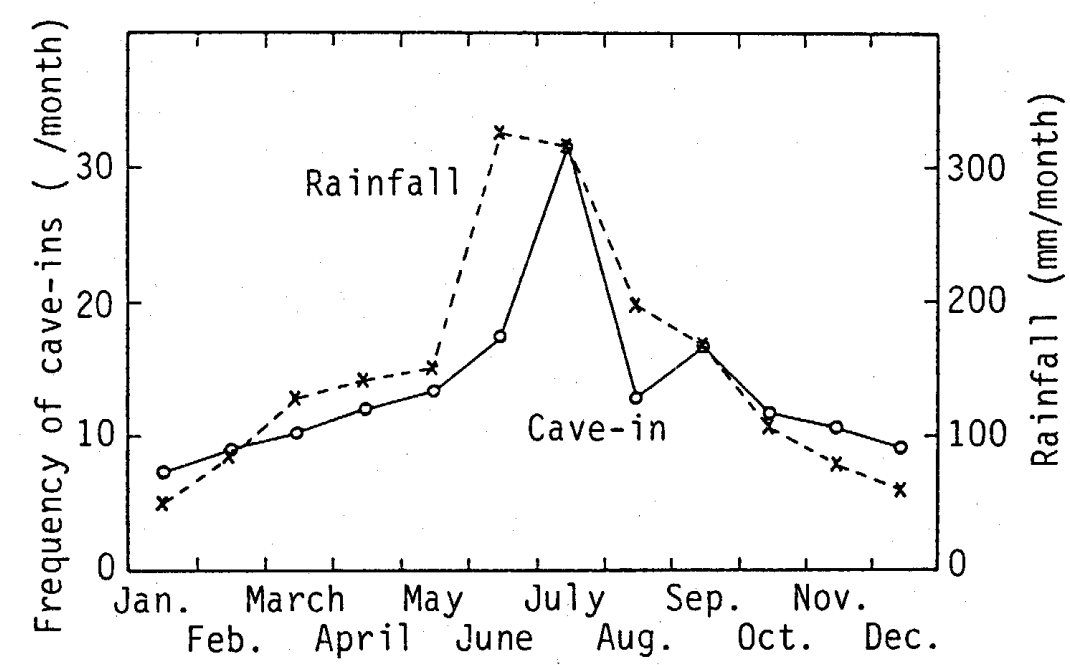

Fig. 1 Average monthly frequency distributions of cave-ins and rainfall in the Chikuho district between 1974 and 1987.

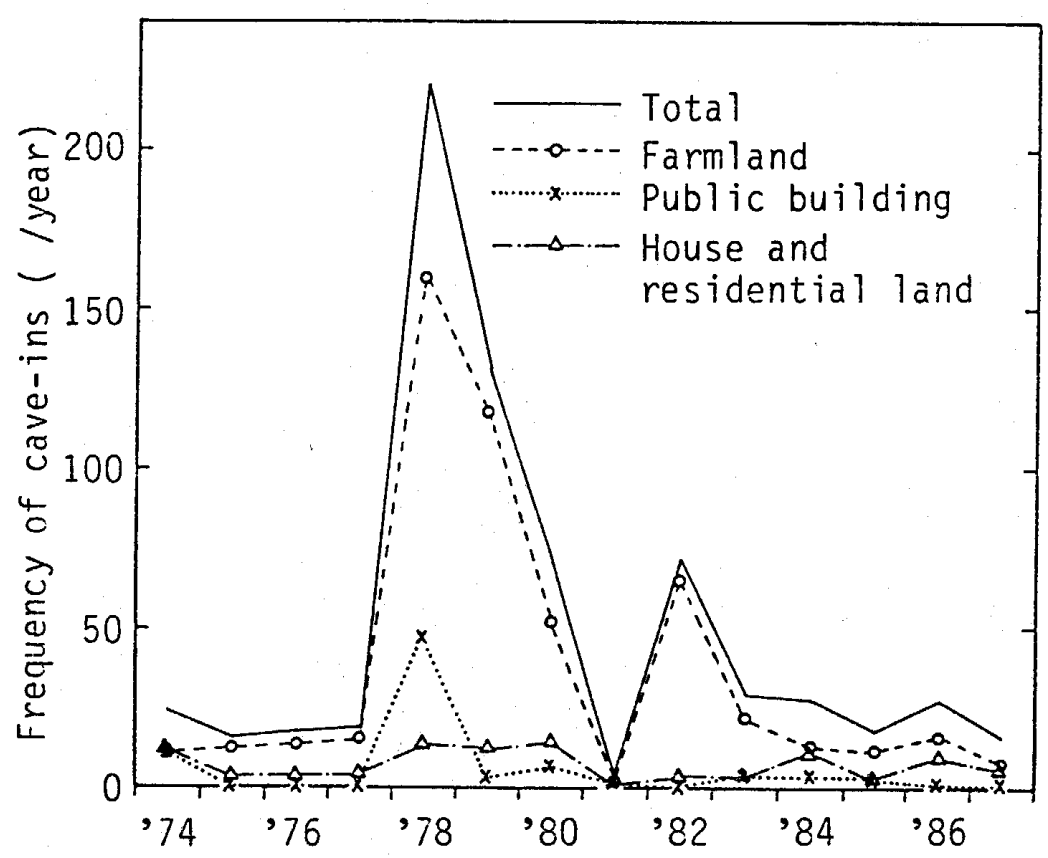

Fig. 2 Frequency distribution of cave-ins in the Tohoku district between 1974 and 1987. 
Earthquakes. To illustrate the effect of earthquakes on cave-in occurrence, an example of the Tohoku district in northeast Japan is presented here. In this district, many lignite mines have been worked at very shallow depths by the pillar and stall mining method in Kitakami, Miyagi, Mogami, Shohnai and Souma coal fields since the 1890s. On June 12, 1978, an earthquake of 7.4 magnitude (the Miyagi-ken-oki earthquake) occurred about $70 \mathrm{~km}$ off the east coast of the Tohoku district. Fig. 2 shows the frequency of cave-ins, occurring in this district from 1974 to 1987 . According to investigations, 15 to 20 cave-ins normally occurred every year but 219 cave-ins occurred in 1978. This unusual increase was attributed to the earthquake. Especially in the Miyagi coal field, the maximum vertical acceleration was about 100 gals and 22 cave-ins occurred in a $5,000 \mathrm{~m}^{2}$ area of farmland just after the earthquake.

Surcharge on the Ground Surface. Surcharge on the ground surface above the cavities existing at shallow depths also has an important influence on the occurrence of cave-ins. The incremental load procedure of the FEM (finite element method) is useful for determining whether cave-in will occur or not. ${ }^{1}$ The occurrence conclusively depends on the extension of the plastic zones above the cavities to the surface.

Numerical calculation realistically to simulate a complex geotechnical situation, such as discontinuities of the ground, however, is still unsatisfied. In this case, it is convenient to study experimentally by physical model tests. Many kinds of physical tests have been tried, such as agar-agar model, trapdoor model and centrifuge model. The base friction technique which is also one of physical model tests is well suited for near-surface problems such as cave-in. Photo. 1 shows a typical result of the experiment of cave-in using the base friction apparatus with air pressure. ${ }^{2)}$

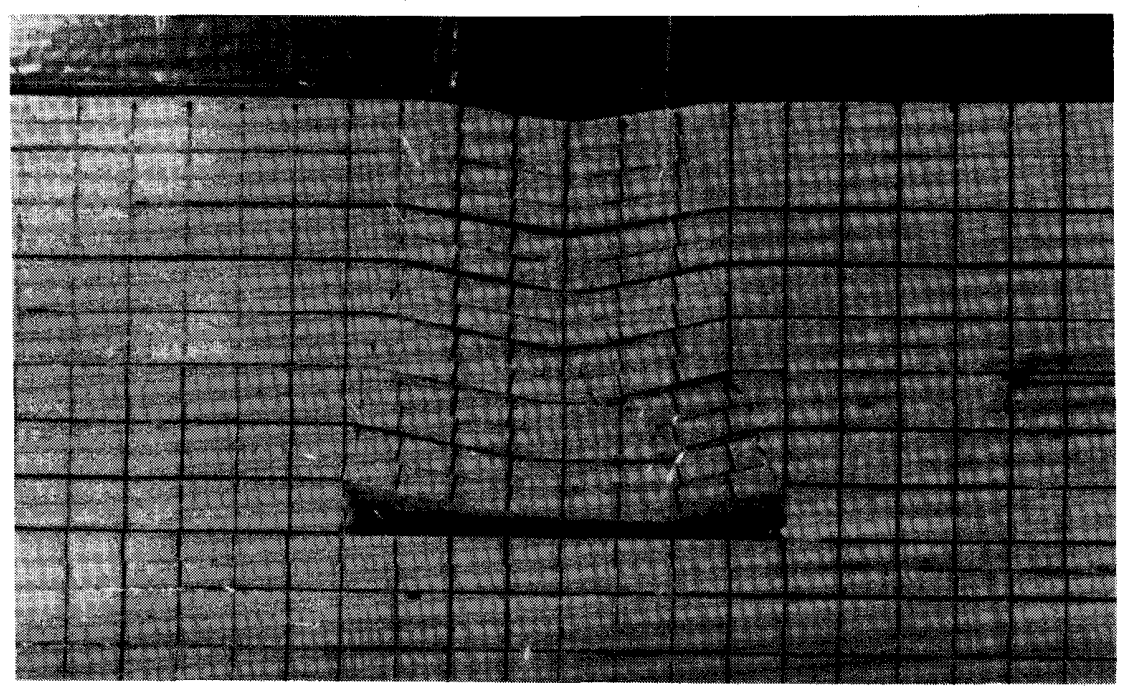

Photo. 1 Typical experimental result of cave-in using the base friction apparatus. 
Preventive Measures against Cave-in. When a heavy structure is built on the ground in which cavities remain at shallow depths, suitable preventive measures against cave-ins must be adopted based on the following conditions: mechanical properties of the ground, depth and width of the cavities, mining method, magnitude and width of loading, cost and the allowable deformation of the structure. ${ }^{3 / 4}$

There are four types of preventive measures which have been examined.

(1) Grouting: It will be undertaken only where the cavities are of a relatively small-scale and remain at shallow depth, because grouting is very expensive.

(2) Excavation and filling: It is used when the cavities exist at relatively shallow depths. This method is more economical than grouting.

(3) Piling until below the floor of the cavities: It can be used for the soft ground, but may not be used for superposing cavities. In this case, the negative friction on piles must be taken into consideration.

(4) Foundation in the form of slab: The foundation to resist cave-ins is relatively expensive but it is very useful in the case of small cavities.

Fig. 3 shows a practical application of grouting, where a structure was planned to construct above cavities remaining at 8 meters depth. ${ }^{1)}$ Although the volume of the cavities were initially estimated at about $800 \mathrm{~m}^{3}$, the total amount of grouting materials came up to $1,170 \mathrm{~m}^{3}$. After grouting, it was confirmed from check borings that the cavities were perfectly filled by grouting materials. As a result of this grouting, the deformation of the foundation of the structure could be considerably reduced.

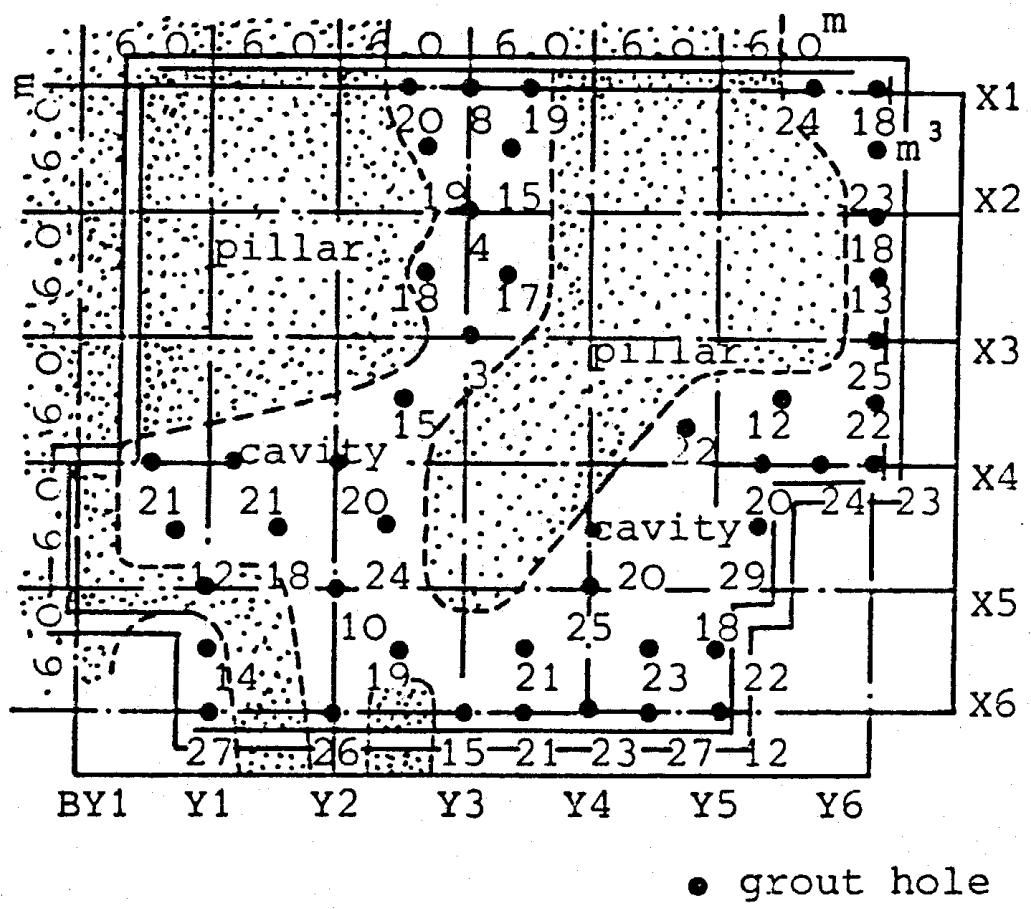

Fig. 3 Distribution of cave-ins and the amount of grouting materials $\left(\mathrm{m}^{3}\right)$. 


\section{Springing out in Old Coal Fields}

Ground water charged in abandoned mines springs out near the outcrop of coal seams, through the goafs remaining at shallow depths or along major faults. This water is called "furutou-sui" in Japanese. Springing out has occurred at least once at more than fifty places in the Chikuho district. This phenomenon of springing out does not only swamp agricultural or residential lands but pollutes rivers with bad quality water.

Typical Patterns of Springing out. Fig. 4 shows a plan view of the goafs and the places of springing out in an area of the Chikuho district. Ground water springs out at lower levels

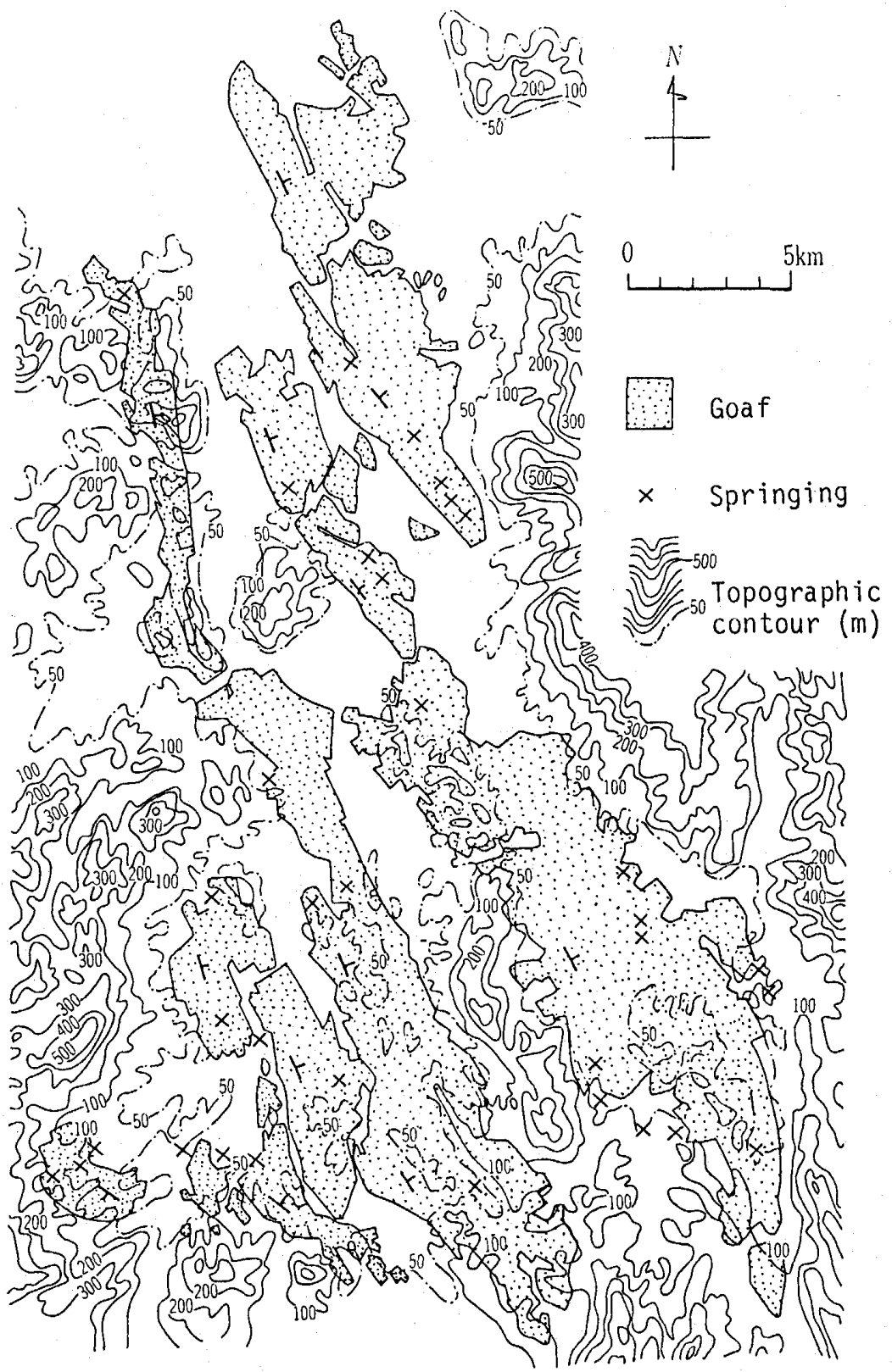

Fig. 4 Distribution of goafs and the places of springing out. 
of the ground surface. Fig. 5 shows the goafs and the contour lines of the water levels which were measured by shutting a section of the goaf in the boreholes with packers. It can be seen that water flows to the northwest and its level gently slopes with the ground surface.

The rate of springing out depends on the piezometric head of ground water (artesian pressure), depth of goafs, permeability of strata and level of the ground surface. It ranges from a degree of damping lands to a few cubic meters per minute at a place. Based on the observations

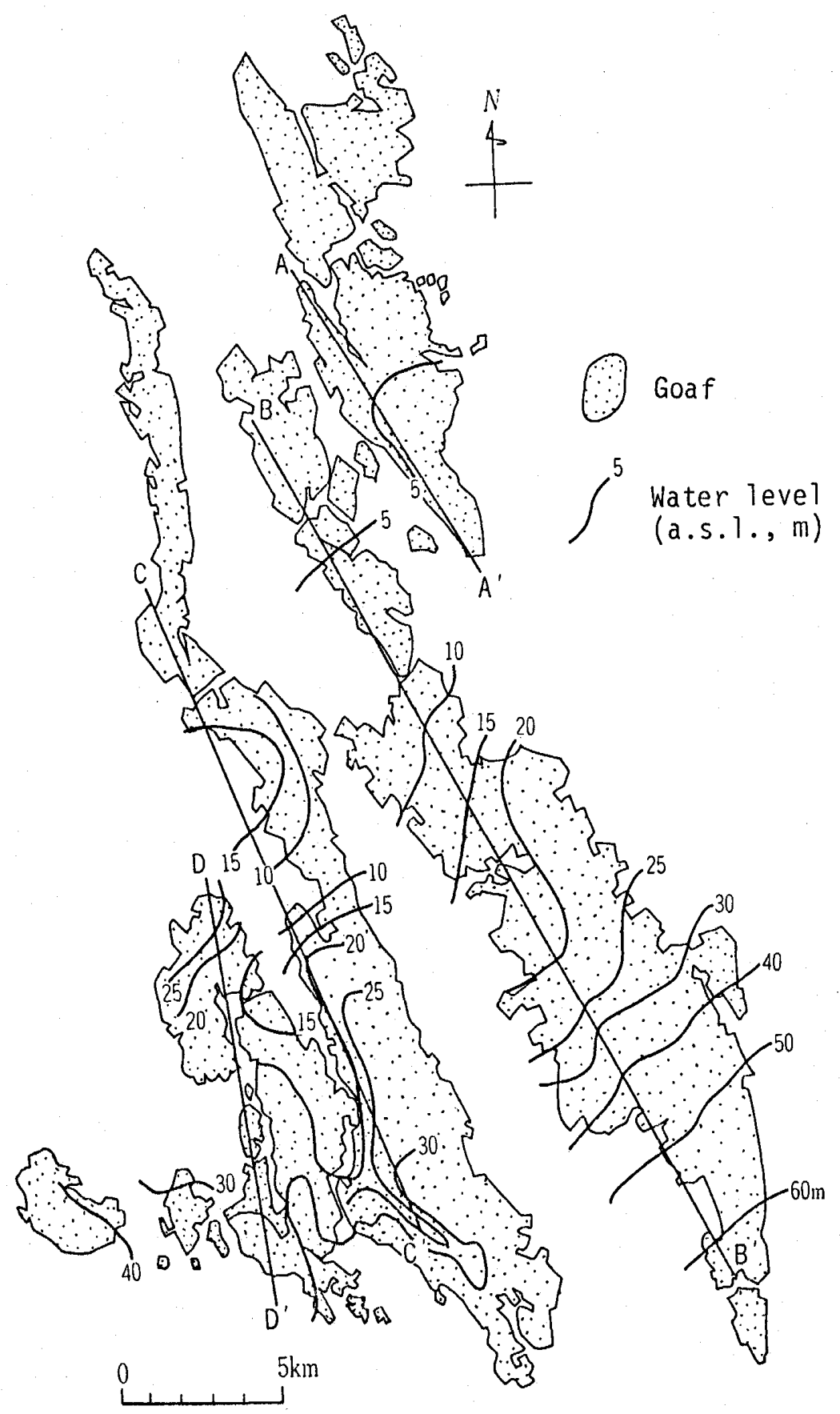

Fig. 5 Distribution of goafs and the contour lines of water levels. 
of 39 places of springing out, its patterns are classified as follows:

(a) Springing out through the most shallow part of goafs or near the outcrop of coal seams (24 places).

(b) Springing out along faults (9 places).

(c) Springing out at portals ( 6 places).

The pattern (a) is the most general because the strata above the goafs are so greatly deteriorated by mining that their permeability is high. At the three places of nine in the pattern (b), water sprang out through the faults developing from the goafs remaining at 20 to 30 meters depth. The. portals in the pattern (c) are of one vertical shaft and of five inclined shafts. When a mine is closed, in general, the portals are sealed to prevent ground water from springing out. This technique can be useful in metal mines but not so in coal mines, because ground water springs out as the pattern (a) when coal seams are mined at shallower depths; metal mines are usually at greater depth than coal mines.

The quality of ground water usually depends on the patterns of springing out mentioned above. Ground water springing out from great depths is of $\mathrm{Na}-\mathrm{HCO}_{3}$ or $\mathrm{Na}-\mathrm{So}_{4}$ type and exhibits an acidic property. On the other hand, water from shallow depths is of $\mathrm{Ca}_{-} \mathrm{So}_{4}$ and its property changes from acidic to neutral because of mixing with rain water.

Permeability of Goafs. Fig. 6 shows the results of the JFT carried out to measure flow rates and head pressures at some sections of a borehole. This borehole was 325 meters in length and penetrated goafs, zones deteriorated by mining and a basement. Three groups of mined coal seams, with a dip of about 10 degrees, were encountered in this investigated area. The borehole and the coal seams are schematically shown in the left of Fig. 6. The Tertiary strata unconformably cover the Paleozoic basement.

It can be seen that the flow rates are great at both the goafs and the deteriorated zones. These zones extend from 40 to 50 meters in height, from the roofs of the goafs; it has been

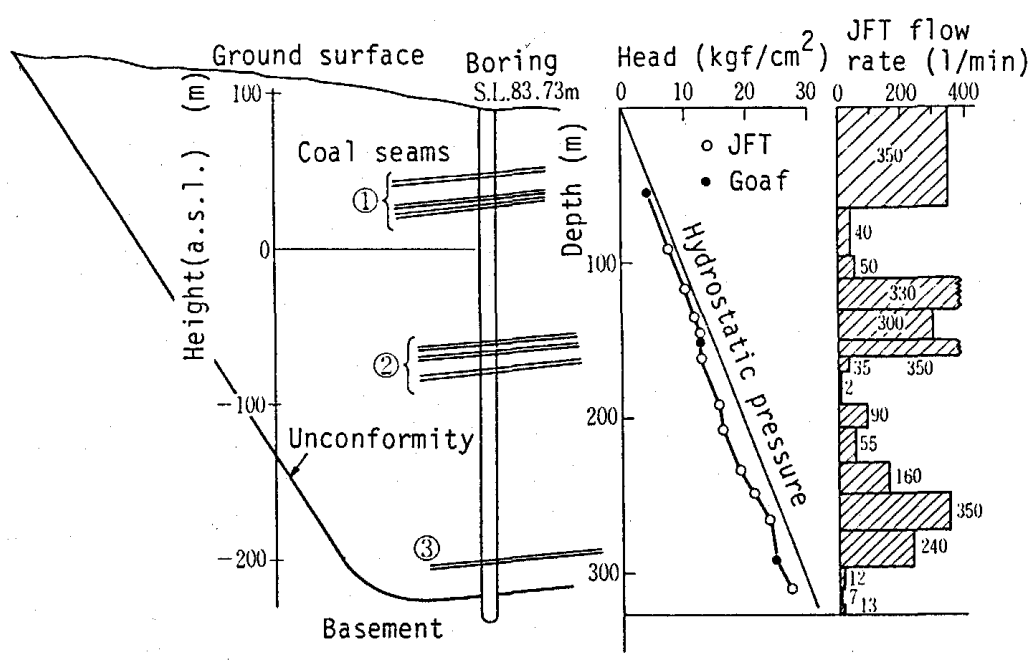

Fig. 6 Result of the JFT. 
found that the deteriorated zones equal 15 to 25 times as high as the goafs in the longwall mining and 2 to 10 times as high as those in the room-and-pillar mining.

The flow rates are 3.5 to $5.0,1.0$ to 1.5 and 1.8 to $2.5 \mathrm{~m}^{3} / \mathrm{min}$ at the outcrops of the three coal seam groups, $0.007 \mathrm{~m}^{3} / \mathrm{min}$ at the boundary between the Tertiary rocks and the basement and $0.013 \mathrm{~m}^{3} / \mathrm{min}$ in the basement. From these flow rates the coefficients of permeability are estimated at $10^{-1}$ to $10^{-2} \mathrm{~cm} / \mathrm{sec}$ in the goafs, $10^{-4} \mathrm{~cm} / \mathrm{sec}$ in the deteriorated zones and $10^{-5}$ to $10^{-6} \mathrm{~cm} / \mathrm{sec}$ in the basement and non-deteriorated zones. It is presumed in the investigated area that three permeable zones are independently formed corresponding to the three groups of coal seams, which are 100 meters distant from each other, and ground water mainly flows parallel to the coal seams.

Analysis of Water Flow by the FEM. Two dimensional analysis of water flow was performed using the FEM to reveal the behavior of ground water both in the cases with and without the goafs in the investigated area. Fig. 7 shows a cross section modeling the area, which was classified as four zones with different permeability: goafs, deteriorated zones, nondeteriorated zones and basements. The coefficients of permeability used in the FEM analysis are also shown in Fig. 7, which were determined based on the result of the JFT. The head pressures corresponding to the level of the ground surface were set at the boundaries of A-B and $\mathrm{C}-\mathrm{D}$ shown in Fig. 7, and it was assumed that ground water can not flow across the

Table 1 Comparison of measured and calculated flow rates.

\begin{tabular}{ccc}
\hline $\begin{array}{c}\text { Group of } \\
\text { coal seams }\end{array}$ & $\begin{array}{c}\text { Calculated values } \\
\left(\mathrm{m}^{3} / \mathrm{min}\right)\end{array}$ & $\begin{array}{c}\text { Measured values } \\
\left(\mathrm{m}^{3} / \mathrm{min}\right)\end{array}$ \\
\hline 1 & 4.9 & $3.5-5.0$ \\
2 & 3.5 & $1.0-1.5$ \\
3 & 3.5 & $1.8-2.5$ \\
\hline
\end{tabular}

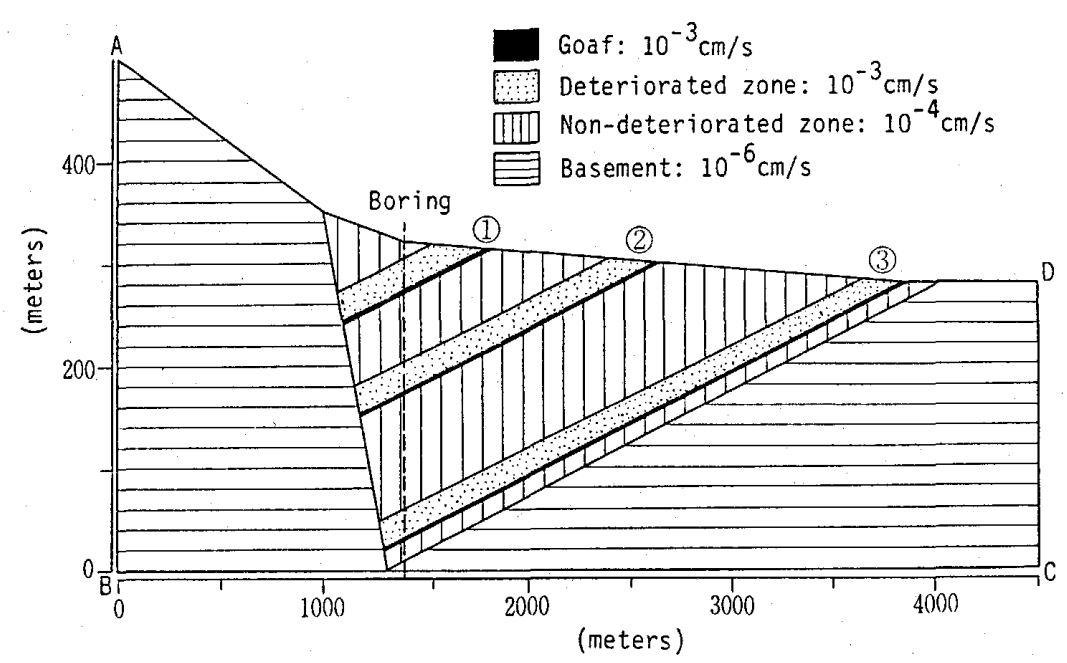

Fig. 7 Modeling of the ground for analysis of water flow. 
boundary B-C.

The flow rates calculated by the FEM are more than the measured ones, as shown in Table 1. Considering a loss of flowing to rivers and subsoils actually, however, there may be no difference between these results. The flow rates calculated in the case that coal seams are completely untouched are considerably less than those in which they are mined. Since the former flow rates are under an evaporating rate $(1,493 \mathrm{~mm}$ per year) in northern Kyushu, it occurs no phenomenon of springing out.

\section{Subsidence in the Area of Thick Alluvium}

The subsidence in the area of the thick alluvium overlying coal seams is occurring at Miike coal field which is located in the southern part of Fukuoka Prefecture in Kyushu Island. In this coal field one colliery is being worked under the sea. The schematic section of the colliery is shown in Fig. 8. The alluvium consists of soft clay and loose sand layers, and its thickness is about 100 to $150 \mathrm{~m}$. This condition is favorable for safety from inundation, but the subsidence is remarkable. The characteristics of this type are as follows:

(1) Subsidence areas are much more wide spread than usual.

(2) The subsidence is not only caused by mining but also by advancing gate roads, and its behavior proceeds rapidly and comes to an end just after mining, comparing with usual subsidence.

(3) It is difficult to distinguish between the subsidence due to mining and the consolidation of clay due to drawing up from deep wells.

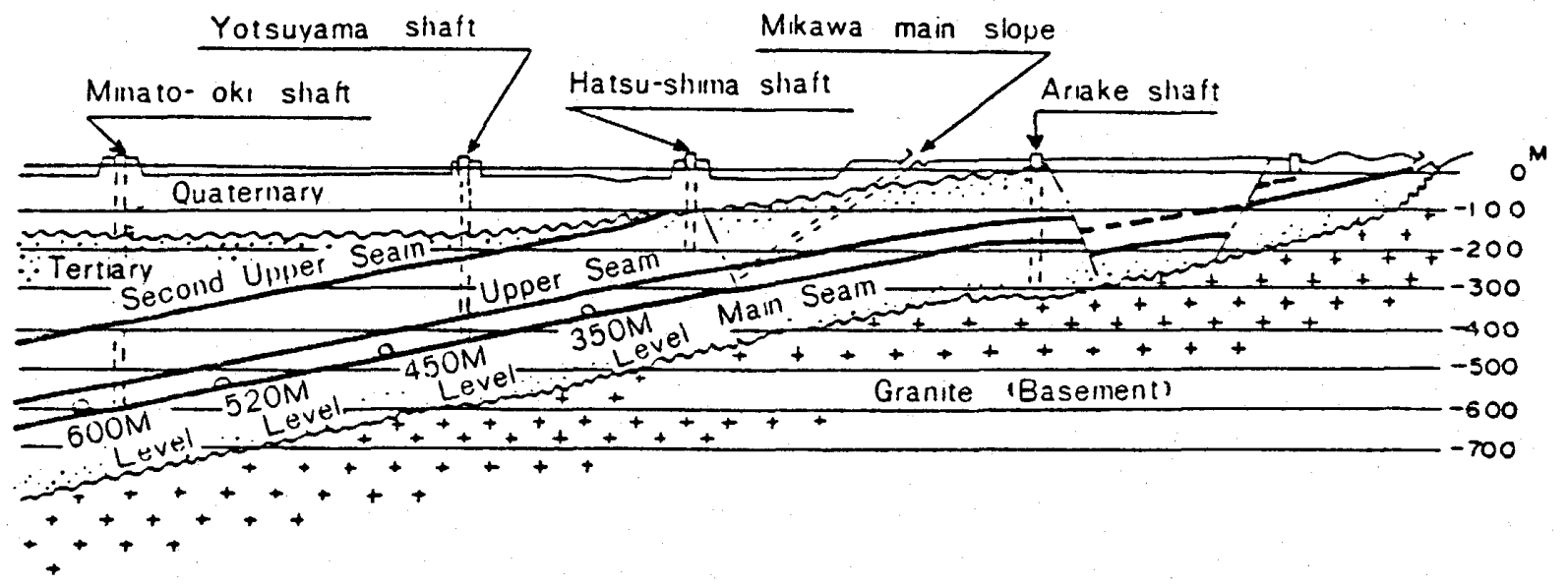

Fig. 8 Schematic section of a colliery working under the sea.

\section{Conclusions}

It was revealed that rainfall, earthquake and surcharge on the ground surface accelerate the occurrence of cave-ins. Since some preventive measures against them have been already propo- 
sed, one of these techniques should be adopted according to the situation of cave-ins. The goafs at abandoned mines act as very permeable zones and control the flow of ground water. It is possible to predict the place where water springs out, but difficult to take preventive measures against the phenomenon. The thick alluvium overlying the mined area causes a remarkable subsidence. This includes the subsidence due to mining and the consolidation of clay, and it is difficult to distinguish between them.

This paper was first prepared for the special lecture at a university in China last October, given by one of the authors, Prof. Tadashi Nishida who had suddenly died on September 1st, 1988. The authors would like to thank the committee of publication at Institute of Advanced Material Study, Kyushu University for kindly offering us to express our deepest regrets for passing away of Prof. T. Nishida.

\section{References}

1) Nishida, T., T. Esaki, N. Kameda and K. Aoki, Cave-in due to mining at shallow depths, Proc. Int. Symp. on Weak Rock, Tokyo, pp.707-712, 1981.

2) Nishida, T., T. Esaki, N. Kameda and Y. Nakagawa, A development of the base friction apparatus for the gravitational model test, The Reports of Research Institute of Industrial Science, Kyushu University, No.74, pp.17-24, 1983 (in Japanese).

3) NCB, Subsidence Engineers' Handbook, National Coal Board, London, 1975.

4) ICE, Ground Subsidence, Institution of Civil Engineers, London, 1977. 